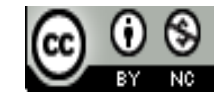

Jurnal Bimbingan Konseling Indonesia is licensed under

A Creative Commons Attribution-Non Commercial 4.0 International License.

\title{
MODEL BIMBINGAN KELOMPOK DENGAN TEKNIK SELF CONTROL UNTUK MEREDUKSI PERILAKU MENYONTEK SISWA SMP NEGERI DI KOTA SINGKAWANG
}

\author{
${\text { Dian } \text { Mayasari }^{1)} \text {, Iip Istirahayu }}^{2)}$ \\ 1) STKIP Singkawang, Singkawang, Indonesia \\ E-mail: diansingkawang@gmail.com \\ ${ }^{2)}$ STKIP Singkawang, Singkawang, Indonesia \\ E-mail:iip_istirahayu@yahoo.com
}

\begin{abstract}
Abstrak. Siswa yang duduk di bangku SMP merupakan siswa yang berada pada usia remaja. Usia dimana terjadi perubahan dalam aspek biologis, psikologis, dan sosial. Dalam menghadapi perubahan yang terjadi siswa harus dapat menyesuaikan diri dengan kondisi dan lingkungan yang ada. Akan tetapi tidak semua siswa dapat menyesuaikan diri dengan tuntutan dan perubahan lingkungan. Ketidakmampuan siswa dalam menyesuaikan diri dengan lingkungan akan menyebabkan timbulnya perilaku bermasalah. Perilaku bermasalah yang dilakukan siswa pada saat proses pembelajaran salah satunya adalah perilaku menyontek. Perilaku menyontek bersifat destruktif dan apabila tidak ditangani akan berdampak pada munculnya masalah dalam belajar maupun kebiasaan siswa untuk menyontek. Mengingat akibat yang akan ditimbulkan dari perilaku menyontek tersebut, membawa pemikiran bahwa perilaku menyontek perlu diatasi agar siswa tidak mengalami akibat serius dari perilaku tersebut. Salah satu usaha yang dilakukan adalah melalui bimbingan kelompok dengan teknik self control. Tujuan dari penelitian ini untuk menemukan model bimbingan kelompok dengan teknik self control untuk mereduksi perilaku bermasalah siswa SMP Negeri Di Kota Singkawang. Metode yang digunakan dalam penelitian ini adalah Research and Development (R\&D). Populasi penelitian ini adalah siswa SMP Negeri Di Kota Singkawang. Jenis data yang digunakan dalam penelitian pengembangan ini adalah data kualitatif yang diperoleh dari hasil wawancara, observasi, DCM, dan validasi ahli. Analisis data dalam penelitian ini menggunakan prosedur kualitatif. Model bimbingan kelompok dengan teknik self control untuk mereduksi perilaku bermasalah tersusun atas 7 komponen: (1) Rasional; (2) Visi dan misi; (3) Tujuan; (4) Isi bimbingan kelompok; (5) Dukungan sistem yang teridiri dari: (a) pengembangan program, (b) pengembangan staf, dan (c) penataan kebijakan, prosedural, dan petunjuk teknis; (6) Peran, fungsi dan kualifikasi konselor, serta (7) Tahapan bimbingan kelompok yang terdiri dari (a) tahap awal, (b) tahap peralihan, (c) tahap kegiatan, (d) tahap pengakhiran, serta (e) evaluasi dan tindak lanjut.
\end{abstract}

Kata Kunci: Bimbingan Kelompok; Teknik Self Control; Perilaku Menyontek

\section{Pendahuluan}

Siswa yang duduk di bangku SMP merupakan siswa yang berada pada usia remaja, usia dimana terjadi perubahan dalam aspek biologis, psikologis, dan sosial. Dalam menghadapi perubahan yang terjadi siswa harus dapat menyesuaikan diri dengan kondisi dan lingkungan yang ada. Akan tetapi tidak semua siswa dapat menyesuaikan diri dengan tuntutan dan perubahan lingkungan. Ketidakmampuan siswa dalam menyesuaikan diri dengan lingkungan akan menyebabkan timbulnya perilaku bermasalah. Hal ini sejalan dengan [1] mengatakan bahwa perilaku anak bermasalah atau menyimpang ini muncul karena penyesuaian yang harus dilakukan anak terhadap tuntutan dan kondisi lingkungan yang baru. [2] menyatakan perilaku bermasalah sebagai perilaku menyimpang (deviant behavior) yaitu perilaku atau berbagai aktivitas yang dianggap illegal, amoral, atau 
dianggap tidak baik yang didalamnya termasuk penyimpangan seksual (sexual deviance), perilaku membahayakan diri (selfharm) dan perilaku membenci kelompok (hate groups). Perilaku bermasalah masih sering terjadi dikalangan siswa.

Jenis-jenis perilaku bermasalah dikalangan siswa diantaranya tidak menyukai satu atau lebih mata pelajaran, suka membolos, suka menunda-nunda mengerjakan atau bahkan mengabaikan tugas-tugas sekolah, malas belajar, dan bermain game online, video game, facebook-an, sms-an secara berlebihan sehingga menggangu waktu belajar [3]. Selain itu, perilaku menyontek juga termasuk salah satu perilaku menyimpang. Athanasou dan Olasehinde sebagaimana dikutip [4] menyebutkan tentang perilaku menyontek adalah kegiatan menggunakan bahan atau materi yang tidak diperkenankan atau menggunakan pendampingan dalam tugas-tugas akademik yang bisa memengaruhi hasil evaluasi atau penilaian. Menyontek dapat menyebabkan hasil evaluasi belajar yang dimiliki oleh siswa tidak sesuai dengan kemampuan sebenarnya.

Perilaku menyontek bersifat destruktif dan apabila tidak ditangani akan berdampak pada munculnya masalah dalam belajar maupun kebiasaan siswa untuk menyontek. Mengingat akibat yang akan ditimbulkan dari perilaku menyontek tersebut, membawa pemikiran bahwa perilaku menyontek perlu diatasi agar siswa tidak mengalami akibat serius dari perilaku tersebut. Salah satu usaha yang dilakukan adalah melalui bimbingan kelompok dengan teknik self control.

Bimbingan kelompok merupakan bantuan yang diberikan kepada sekelompok siswa dengan memanfaatkan dinamika kelompok untuk membantu anggota-anggota kelompok mencapai tujuan bersama. Adapun sifat bimbingan kelompok dimulai dari yang bersifat informatif sampai yang pada sifatnya teraupetik. Gadza (dalam [5]) menyatakan bahwa bimbingan kelompok diorganisasikan untuk mencegah perkembangan masalah, yang isi utamanya meliputi informasi pendidikan, pekerjaan, pribadi, dan masalah social yang tidak disajikan dalam bentuk pelajaran. Dengan bimbingan kelompok diharapkan siswa dapat berbagi informasi yang akurat sehingga membantu mereka dalam mengatasi perilaku bermasalah.

Ada berbagai macam teknik yang bisa digunakan dalam bimbingan kelompok, salah satunya adalah teknik self control. Self control menurut [6] merupakan pengendalian diri individu terhadap waktu tunda penerimaan imbalan. Dengan self control, siswa dilatih untuk merancang lingkungan yang menyebabkan peluang terjadinya perilaku bermasalah berkurang bahkan hilang sama sekali, sekaligus peluang terjadinya perilaku tidak bermasalah meningkat.

Informasi yang diperoleh berdasarkan wawancara pada saat pendampingan PPL di Sekolah, Bimbingan kelompok pada umumnya sudah dilaksanakan di beberapa SMP di kota singkawang, namun bimbingan kelompok dengan teknik self control untuk mereduksi perilaku menyontek belum pernah dilakukan. Atas dasar tersebut peneliti tertarik untuk meneliti tentang bimbingan kelompok dengan teknik self control untuk mereduksi perilaku menyontek siswa SMP Negeri di Kota Singkawang.

\section{METODE}

Metode yang digunakan dalam penelitian ini adalah Research and Development (R\&D). Populasi penelitian ini adalah siswa SMP Negeri Di Kota Singkawang. Jenis data yang digunakan dalam penelitian pengembangan ini adalah data kualitatif yang diperoleh dari hasil wawancara, observasi, DCM, dan validasi ahli. Untuk menguji kelayakan model hipotetik, peneliti melaksanakan uji ahli dan uji praktisi. Uji ahli dilakukan oleh pakar bimbingan dan konseling, sedangkan uji praktisi dilakukan oleh guru Bimbingan dan Konseling. Analisis data penelitian dilakukan dengan menggunakan prosedur kualitatif. Prosedur kualitatif dilakukan untuk memaknai deskripsi kondisi objektif pelaksanaan layanan bimbingan kelompok di sekolah. Hasil analisis ini dijadikan dasar untuk menyusun model hipotetik awal. Selanjutnya, melakukan uji kelayakan model dengan mempertimbangkan masukan dari validator ahli dan praktisi. Hasil dari analisis ini digunakan untuk melakukan perbaikan dari model hipotetik awal (model teruji 1). Data pada tahap ketiga dianalisis dengan prosedur kualitatif. Bentuk analisis kualitatif dilakukan dengan menelaah proses penerapan yang dikembangkan. Hasil dari analisis ini digunakan sebagai dasar untuk mereduksi perilaku bermasalah siswa.

\section{HASIL DAN PEMBAHASAN}

\section{A. HASIL}

Model bimbingan kelompok dengan teknik self control dikembangkan berdasarkan analisis hasil studi pendahuluan antara temuan empiris di lapangan (yaitu kondisi objektif pelaksanaan layanan bimbingan kelompok dan perilaku menyontek siswa di SMP Negeri Singkawang) dengan kaidahkaidah layanan bimbingan kelompok yang bersifat konseptual (yaitu kajian teoritik, hasil-hasil penelitian, dan ketentuan formal pelaksanaan layanan bimbingan kelompok di SMP yang dirancang secara kolaboratif). Untuk menghasilkan model bimbingan kelompok dengan teknik self control yang teruji secara efektif, maka diperlukan adanya uji kelayakan model secara rasional.

Model bimbingan dan kelompok telah divalidasi oleh 3 (tiga) ahli bimbingan dan konseling. Aspek yang dinilai oleh validator ahli terdiri dari 7 aspek antara lain: rasional, tujuan, isi model, tahap-tahap pelaksanaan, evaluasi dan tindak lanjut. Adapun hasil validasi oleh masing-masing pakar dan praktisi dapat dideskripsikan sebagai berikut:

TABEL I

VALIDASI OLEH PAKAR BIMBINGAN DAN KONSELING

\begin{tabular}{ccll}
\hline Pakar & Skor & Simpulan & $\begin{array}{l}\text { Komentar, saran, } \\
\text { dan Perbaikan }\end{array}$ \\
\hline 1 & 47 & $\begin{array}{l}\text { Model ini membutuhkan } \\
\text { beberapa perbaikan } \\
\text { sebelum digunakan }\end{array}$ & $\begin{array}{l}\text { Ada bagian draf model } \\
\text { tidak menjadi item } \\
\text { untuk penilaian } \\
\text { validasi. }\end{array}$ \\
\hline 2 & 51 & $\begin{array}{l}\text { Model ini sudah siap } \\
\text { digunakan dengan sedikit } \\
\text { perbaikan }\end{array}$ & $\begin{array}{l}\text { Model sudah dapat } \\
\text { langsung diterapkan di } \\
\text { lapangan. }\end{array}$ \\
\hline 3 & 50 & $\begin{array}{l}\text { Model ini membutuhkan } \\
\text { beberapa perbaikan } \\
\text { sebelum digunakan }\end{array}$ & $\begin{array}{l}\text { Model sudah layak } \\
\text { untuk uji keefektifan }\end{array}$ \\
\hline
\end{tabular}


Beberapa masukan yang diberikan oleh pakar ahli Bimbingan dan Konseling tersebut digunakan oleh peneliti dalam merevisi model bimbingan kelompok dengan teknik self control. Selain mendapat masukan dari pakar ahli Bimbingan dan Konseling, peneliti juga melakukan validasi kepada para pakar di lapangan. Hal ini dilakukan agar bimbingan kelompok dengan teknik self control yang peneliti susun dapat disesuaikan dengan kondisi lapangan serta dapat digunakan oleh para praktisi yang ada di lapangan. Adapun

TABEL II yang divalidasi oleh para praktisi antara lain kontribusi model terhadap tujuan pendidikan dan tujuan bimbingan konseling, peluang keterlaksanaan, kemampuan konselor dalam menerapkan model, kesesuaian model dengan karakteristik siswa, kepraktisan model untuk dipahami, tahap-tahap pelaksanaan model dan peluang keterjalinan kerjasama dalam pelaksanaan model. Berikut adalah beberapa masukan dari para praktisi yang peneliti temui di lapangan.

VALIDASI OLEH PRAKTISI BIMBINGAN DAN KONSELING

\begin{tabular}{|c|c|c|c|c|}
\hline Praktisi & Total Skor & Nilai & Simpulan & $\begin{array}{c}\begin{array}{c}\text { Komentar, saran dan } \\
\text { Perbaikan }\end{array} \\
\end{array}$ \\
\hline 1 & 19 & Baik & $\begin{array}{l}\text { Model ini membutuhkan sedikit } \\
\text { perbaikan sebelum digunakan }\end{array}$ & $\begin{array}{l}\text { Model self control sudah baik dan sesuai digunakan dalam } \\
\text { mengatasi masalah siswa menyontek melalui layanan bimbingan } \\
\text { kelompok. }\end{array}$ \\
\hline 2 & 19 & Baik & $\begin{array}{l}\text { Model ini membutuhkan sedikit } \\
\text { perbaikan sebelum digunakan }\end{array}$ & $\begin{array}{l}\text { Model bimbingan kelompok dengan teknik self control untuk } \\
\text { mereduksi perilaku menyontek baik untuk diterapkan }\end{array}$ \\
\hline 3 & 19 & Baik & $\begin{array}{l}\text { Model ini membutuhkan sedikit } \\
\text { perbaikan sebelum digunakan }\end{array}$ & Model ini bisa diimplementasikan \\
\hline 4 & 18 & Baik & $\begin{array}{l}\text { Model ini membutuhkan sedikit } \\
\text { perbaikan sebelum digunakan }\end{array}$ & Model ini bisa diimplementasikan \\
\hline 5 & 21 & $\begin{array}{l}\text { Sangat } \\
\text { baik }\end{array}$ & $\begin{array}{l}\text { Model ini sudah siap digunakan } \\
\text { dengan sedikit perbaikan sesuai } \\
\text { saran }\end{array}$ & Model ini siap dipraktekkan \\
\hline 6 & 20 & Baik & $\begin{array}{l}\text { Model ini membutuhkan sedikit } \\
\text { perbaikan sebelum digunakan }\end{array}$ & Model ini siap dipraktekkan \\
\hline 7 & 18 & Baik & $\begin{array}{l}\text { Model ini membutuhkan sedikit } \\
\text { perbaikan sebelum digunakan }\end{array}$ & Model ini sudah baik untuk dilaksanakan \\
\hline 8 & 18 & Baik & $\begin{array}{l}\text { Model ini membutuhkan sedikit } \\
\text { perbaikan sebelum digunakan }\end{array}$ & Model ini sudah bisa dilaksanakan \\
\hline 9 & 18 & Baik & $\begin{array}{l}\text { Model ini membutuhkan sedikit } \\
\text { perbaikan sebelum digunakan }\end{array}$ & Model ini sudah bisa dilaksanakan \\
\hline 10 & 19 & Baik & $\begin{array}{l}\text { Model ini membutuhkan sedikit } \\
\text { perbaikan sebelum digunakan }\end{array}$ & Model ini siap dipraktekkan \\
\hline 11 & 19 & Baik & $\begin{array}{l}\text { Model ini membutuhkan sedikit } \\
\text { perbaikan sebelum digunakan }\end{array}$ & Model ini bisa diimplementasikan \\
\hline 12 & 20 & Baik & $\begin{array}{l}\text { Model ini membutuhkan sedikit } \\
\text { perbaikan sebelum digunakan }\end{array}$ & Model ini siap dipraktekkan \\
\hline 13 & 21 & $\begin{array}{l}\text { Sangat } \\
\text { Baik }\end{array}$ & $\begin{array}{l}\text { Model ini sudah siap digunakan } \\
\text { dengan sedikit perbaikan sesuai } \\
\text { saran }\end{array}$ & Model ini sudah sangat baik untuk diterapkan \\
\hline 14 & 20 & Baik & $\begin{array}{l}\text { Model ini membutuhkan sedikit } \\
\text { perbaikan sebelum digunakan }\end{array}$ & Model ini bisa diimplementasikan \\
\hline 15 & 21 & $\begin{array}{l}\text { Sangat } \\
\text { Baik }\end{array}$ & $\begin{array}{l}\text { Model ini sudah siap digunakan } \\
\text { dengan sedikit perbaikan sesuai } \\
\text { saran }\end{array}$ & Model ini sudah sangat baik untuk diterapkan \\
\hline 16 & 21 & $\begin{array}{l}\text { Sangat } \\
\text { Baik }\end{array}$ & $\begin{array}{l}\text { Model ini sudah siap digunakan } \\
\text { dengan sedikit perbaikan sesuai } \\
\text { saran }\end{array}$ & Model ini bisa diimplementasikan \\
\hline 17 & 19 & Baik & $\begin{array}{l}\text { Model ini membutuhkan sedikit } \\
\text { perbaikan sebelum digunakan }\end{array}$ & Model ini siap dipraktekkan \\
\hline
\end{tabular}

Berdasarkan hasil penilaian oleh 3 orang pakar ahli dan 17 orang pakar praktisi, model kelompok dengan teknik self control yang dikembangkan terdiri dari 7 komponen utama, yaitu:

1. Rasional yang menjelaskan secara rinci alasan peneliti dalam mengembangkan model layanan.
2. Visi dan misi model yang memuat rumusan secara implisit ataupun eksplisit yang akan dijangkau konselor dalam mengimplementasikan model layanan.

3. Tujuan yang ingin dicapai dalam pengembangan model Tujuan dibagi menjadi tujuan umum dan tujuan khusus yang keduanya terfokus untuk mereduksi perilaku menyontek siswa. 
4. Isi bimbingan kelompok yang berfokus pada masalah pribadi, sosial, belajar, dan karir.

5. Dukungan sistem, yaitu kegiatan-kegiatan manajemen yang diarahkan pada pengambangan program, pengembangan staf, serta penataan kebijakan, prosedur, dan petunjuk teknis.

6. Peran, fungsi, dan kualifikasi konselor dalam bimbingan kelompok dengan teknik self control.

7. Tahap bimbingan kelompok, yaitu tahap-tahap yang akan dilalui dalam pelaksanaan bimbingan kelompok yang terdiri dari tahap awal, tahap peralihan, tahap kegiatan serta tahap pengakhiran. Evaluasi dan tindak lanjut dimaksudkan untuk mengetahui sejauhmana bimbingan kelompok yang telah dilaksanakan mencapai hasil, dan tindakan apa yang selanjutnya akan dilakukan pemimpin kelompok. Evaluasi yang dilakukan terdiri dari evaluasi hasil (laiseg, evaluasi jangka pendek, dan evaluasi jangka panjang) dan evaluasi proses.

\section{B. PEMBAHASAN}

Model bimbingan kelompok dengan teknik self control merupakan pengembangan bimbingan kelompok dengan menggunakan teknik pada tahap pelaksanaan yang bertujuan untuk mereduksi perilaku menyontek. Bimbingan kelompok dengan teknik self control dipilih sebagai salah satu alternatif untuk mereduksi perilaku bermasalah (perilaku menyontek), dilandasi asumsi bahwa teknik ini dapat mengelola masalah yang berkaitan dengan perilaku bermasalah. Sesuai dengan hasil penelitian [7] yang menemukan pelatihan kendali diri mampu mereduksi secara signifikan kenakalan dan perilaku bermasalah.

Beberapa penelitian tentang peran pelatihan kendali diri untuk mengatasi perilaku bermasalah antara lain diungkapkan oleh [8] yang menemukan bahwa para perokok yang telah melakukan latihan pengendalian diri dengan melakukan kegiatan-kegiatan kecil yang memerlukan pengendalian diri, mampu lebih lama untuk tidak merokok jika dibandingkan dengan perokok yang melakukan kegiatan-kegiatan yang tidak memerlukan pengendalian diri.

\section{KESIMPULAN}

Model bimbingan kelompok dengan teknik self control untuk mereduksi perilaku bermasalah (perilaku menyontek) siswa yang terdiri dari 7 komponen sebagai berikut: (1) Rasional, (2) Visi dan misi, (3) Tujuan, (4) Isi bimbingan kelompok, (5) Pendukung sistem, (6) Peran, fungsi, dan kualifikasi konselor, dan (7) Tahapan bimbingan kelompok yang terdiri dari tahap awal, tahap peralihan, tahap kegiatan, tahap pengakhiran, dan evaluasi tindak lanjut.

\section{DAFTAR PUSTAKA}

[1] Hurlock, E. B. (2004). Developmental Psychology. Jakarta: Erlangga.

[2] McDonald, H.S., Horstmann, B.S., Nicole., Strom, K. J., Pope, M.S. \& Mark W. (2009). The Impact of the Internet on Deviant Behavio and Deviant Communities. Literature Review, Institute for Homeland, Scurity Solution, Applied Reaserch, Focused Result

[3] Gading, I. K. (2013). Pelatihan Kendali Diri untuk Mereduksi Beberapa Perilaku Bermasalah Di Kalangan Para Siswa. Prosiding
Kongres XII, Konvensi Nasional XVIII ABKIN dan Seminar Internasional Konseling 9 (pp. 47-53).

[4] Hartanto, D. (2012). Bimbingan \& Konseling Menyontek: Mengungkap Akar Masalah dan Solusinya. Jakarta: Indeks.

[5] Mayasari, D. (2015). Pengembangan Model Bimbingan Kelompok Dengan Teknik Self Management Untuk Mengurangi Kecemasan Komunikasi Interpersonal Siswa SMP Negeri Pontianak. Jurnal Bimbingan Konseling, 4(1).

[6] Steel, P. (2007). The nature of procrastination: A metaanalytic and theoretical review of quintessential selfregulatory failure. Psychological Bulletin, 133(1), 65-94.

[7] Piquero, A. R., Jennings, W. G., \& Farrington, D. P. (2010). Selfcontrol interventionsfor children under age 10 for improving selfcontrol and delinquency and problem behaviors.Campbell Systematic Reviews 2010:2.

[8] Muraven, M. (2010). Building Self-Control Leads to Improved SelfControl Performance. Journal Experimental Social Psychology 2010 March 1; 46 (2); 465-468. 